\title{
Atatürk Tarafından Yabancı Devlet Başkanlarına Verilen Hediyeler
}

\author{
Yrd. Doç. Dr. Mehmet OKUR*
}

\begin{abstract}
ÖZET
Mustafa Kemal Paşa, savaş alanlarında gösterdiği başarısını barış ve siyasette de göstermiş, milli mücadele yıllarında Türkiye'nin çeşitli yerlerini işgal eden devletlerle dahi diyalog yollarını aramış ve sorunların barış̧ yollarla çözümlenmesi için yoğun çaba harcamıştır.

Mustafa Kemal Paşa'nın bu barış̧̧ı çabaları milli mücadelenin kazanılması ve Yeni Türk devletinin kurulmasından sonra daha belirgin şekilde ortaya çıkacaktır. Zamanın bütün devlet başkanlarıyla temasa geçen Atatürk, onların bazılarını Türkiye'ye davet etmiş, onları en samimi şekilde karşılamış ve çeşitli hediyeler sunmuştur. Diğerleriyle de mektuplaşmak suretiyle sicak ilişkiler kurmaya, dünya barışına katkıda bulunmaya çalışmıştır.

Bu çalışmada Atatürk tarafından yabancı devlet başkanlarına verilen hediyeler ve bu bağlamda liderler arasında kurulan yakın ilişkilere değinilecektir.

Anahtar Kelimeler: Atatürk, Yabancı Devlet Başkanları, Hediye, Yakın İlişkiler, Barış̧̧ Çabalar
\end{abstract}

\section{The Gift Given To Foreign Presidents By Atatürk}

\section{ABSTRACT}

Mustafa Kemal Paşa, succesfull commander in battlefield, kept on this success in peace and politics. He, also, tried to establish a dialogue with the states which invaded different part of Turkey in the national struggle, and spent intense effort to solve the problems in peaceful ways.

\footnotetext{
• Karadeniz Teknik Üniversitesi Fen-Edebiyat Fakültesi Tarih Bölümü.
} 
After the accomplishment of the national struggle and the foundation of the new Turkish state, Mustafa Kemal Paşa's appeared this pacific efforts more evidently. M. Kemal Atatürk contacted the whole contemporary president and invited some of them to Turkey. He greeted them guite sincerely and presented them different gifts. And he, also, tried to establish warm relation by means of correspondence with other statesmen.

In this study we will mention about the gifts given by Atatürk to the foreign presidents and warm relations between $M$. Kemal Atatürk and this statemen in this connnection.

Key Words: Atatürk, Foreign Presidents, Gift Warm, Relations, Pacific Efforts

Mustafa Kemal Paşa, savaş alanlarında gösterdiği başarısını barış ve siyasette de göstermiş, milli mücadele yıllarında Türkiye'nin çeşitli yerlerini işgal eden devletlerle dahi diyalog yollarını aramış ve sorunların barışçı yollarla çözümlenmesi için yoğun çaba harcamıştır.

Mustafa Kemal Paşa'nın bu barışçı çabaları milli mücadelenin kazanılması ve Yeni Türk devletinin kurulmasından sonra daha belirgin şekilde ortaya çıkacaktır. Zamanın bütün devlet başkanlarıyla temasa geçen Atatürk, onların bazılarını Türkiye'ye davet etmiş, onları en samimi şekilde karşılamış ve çeşitli hediyeler sunmuştur. Diğerleriyle de mektuplaşmak ve hediye göndermek suretiyle sıcak ilişkiler kurmaya, dünya barışına katkıda bulunmaya çalışmıştır.

$\mathrm{Bu}$ çalışmada, elde edebildiğimiz dokümanlar çerçevesinde Atatürk tarafından yabancı devlet başkanlarına sunulan çeşitli hediyelere ve bu vesile ile kurulan yakın ilişkilere değinilecektir.

\section{I- Afganistan Emiri Amanullah Han'a Sunulan Hediyeler}

Türkiye-Afganistan arasındaki ilk ilişkiler Türkiye Büyük Millet Meclisi Hükümeti'nin Ağustos 1920'de Abdurrahman Bey'i Afganistan'a temsilci göndermesiyle başlamış ${ }^{1} 1$ Mart 1921 'de Moskova'da imzalanan Türk-Afgan Dostluk Antlaşmasıyla ivme kazanmıştır. ${ }^{2}$

Afgan Kralı Amanullah Han Milli Mücadele boyunca Türk milletinin yanında olmuş, Türk ordusunun başarılarını alkışlamış, başta Mustafa Kemal Paşa olmak üzere Türk komutanlarına çeşitli nişanlar göndermiştir. ${ }^{3}$

' Bilal N. Şimşir, Atatürk ve Yabancı Devlet Başkanları I, Ankara, 1993, s. 5.

2 Mehmet Saray, Afganistan ve Türkler, İstanbul, 1987, s. 94; İsmail Soysal, Türkiye'nin Siyasal Andlaşmaları I (1920-1945), Ankara, 1989, s. 25-26.

3 Utkan Kocatürk, Doğumundan Ölümüne Kadar Kaynakçalı Atatürk Günlüğü, Ankara, 1988, s. 231 . 
Türkiye ile Afganistan arasındaki dostluk ilişkileri Cumhuriyetin ilanından sonra da devam etmiştir. Türkiye devletinin yönetim şeklinin "Cumhuriyet" olarak belirlenmesi ve Mustafa Kemal Paşa'nın Cumhurbaşkanı seçilmesi Afganistan'da büyük bir memnuniyetle karşılanmış, ${ }^{4}$ Cumhuriyet Türkiye'sinin hukuk, eğitim, kültür ve sosyal alanlarda gerçekleştirdiği yapısal reformlar Afgan yöneticileri tarafından dikkatle ve takdirle izlenmiştir.

Türkiye Cumhuriyeti Reisicumhuru Mustafa Kemal Paşa da Afganistan'ın bağımsızlık günü yıldönümlerini kutlamış ${ }^{6}$ ve bu samimi dostluğun bir göstergesi olarak Ocak 1926'da gümüş çerçeve içersinde bir resmini Amanullah Han'a göndermiştir.?

Ayrıca Türkiye devleti, kardeş Afganistan'a öğretmen, subay ve doktor gibi teknik uzmanlar göndermiş ve Afgan gençlerinin Türk üniversitelerinde eğitim görmesini sağlamıştır. ${ }^{8}$ Yine Türkiye 17 Kasım 1926 tarihli bakanlar kurulu kararıyla Afgan ordusunun güçlenmesine katkıda bulunmak için iki bin İngiliz tüfeği, tam teçhizatlı dört makineli tüfek ve beş yüz bin fişek hediye olarak gönderilmiştir. ${ }^{9}$

Afgan Kralı Amanullah Han'ın Mayıs 1928'de Türkiye'ye yaptığı ziyaret ise $^{10}$ Türk-Afgan ilişkilerini zirveye ulaştıran bir gelişme olmuştur. Mustafa Kemal Paşa, Türkiye'ye gelen ilk devlet başkanı olması dolayısıyla

${ }^{4}$ Bu münasebetle Afganistan'ın Ankara Büyükelçisi Sultan Ahmet Han'ın Hariciye Vekâleti'ne gönderdiği telgrafta "Necip Türk milletinin mücahede ve inkılâp sahasında şu on dört yıl içinde ihraz ettiği hârikânisar zafer ve muvaffakiyetlerin semere-i hoşgüvârı ve meyil ve istidad-1 medenisinin bir tecellisi olmak üzere Türkiye Büyük Millet Meclisi tarafından bu kere Türkiye şekli hükümetinin cumhuriyete taklib ve Gazi Mustafa Kemal Paşa Hazretlerinin ittifak-1 ara ile bu cumhuriyete reis intihab olunması garp afakında olduğu gibi şarkta İslam aleminde, alelhusus Türk milletine kendisini hakiki ve samimi bir rabıta ile bağlamış olan Afgan milletinin ruhunda pek derin ihtisas ve in'ikaslar uyandıracağı şüphesizdir. Sema-i İslamda Türkün birinci defa doğan şu cumhuriyet yıldızı yeryüzünde bütün İslam milletlerini feyizli ve ümitbahş ziyalarıyla ışıklandıracağına imanımız vardır." demekteydi. (Şimşir, Atatürk ve Yabancı Devlet Başkanlanı I, 13).

${ }^{5}$ Hikmet Öksüz, "Türkiye Cumhuriyeti Devleti’nin İlk Resmi Konuğu: Emanullah Han'ın Türkiye Ziyareti (20 Mayıs-2Haziran 1928)", Pax Ottomana, Studies in Memorian Prof. Dr. Nejat Göyünç, Sota-Yeni Türkiye, Haarlem-Ankara, 2001, s. 769.

${ }^{6}$ Şimşir, Atatürk ve Yabancı Devlet Başkanları I, s. 20-24.

${ }^{7}$ Şimşir, Atatürk ve Yabancı Devlet Başkanları I, s. 18.

${ }^{8}$ Fahir Armaoğlu, 20. Yüzyıl Siyasi Tarihi, İstanbul, Basım Tarihi Yok, s. 331.

${ }^{9}$ Başbakanlık Cumhuriyet Arşivi (BCA), 030.18.01/02.66.916.

${ }^{10}$ Afgan Kralı Amanullah Han, 1927 yılının Aralık ayında Kraliçe Melike Süreyya, kızı ve kayınvalidesi ile birlikte oldukça uzun sayılabilecek bir yurt dışı seyahatine çıktı. Ziyaret edeceği ülkeler çoğunlukla Avrupa ülkeleriydi. Deniz yoluyla başlatacağı ziyaret için önce Hindistan'a gitti. Oradan Hint Okyanusu ve Kızıldeniz yoluyla Mısır'a geçti. Buradan İtalya'ya geçen Amanullah Han, Fransa, Belçika, İsviçre, Almanya ve İngiltere'yi ziyaret ettikten sonra Polonya üzerinden Sovyet Rusya'ya oradan da Türkiye'ye geldi. (Öksüz, Türkiye Cumhuriyeti Devleti'nin İlk Resmi Konuğu: Emanullah Han, s. 770-771). 
Afgan Kralının ziyaretine büyük önem vermiş, Kralın herhangi bir hükümdar gibi değil, değerli bir kardeş gibi karşılanacağını ifade etmiştir." Nitekim hazırlıklar günlerce önce başlamış, Kral ve Kraliçeye uygulanacak program ve takdim edilecek hediyeler belirlenmiştir. ${ }^{12}$

19 Mayıs 1926 'da İstanbul ve 20 Mayıs'ta Ankara'da coşkulu törenlerle karşılanan Amanullah Han'a ziyaret boyunca yakın ilgi gösterilmiş ${ }^{13}$ ve Türkiye'den ayrılırken kendilerine, ipekten bir muhafaza örtüsü içinde ipekten yapılmış eski usul hesap işi işlemeli bir elbise ile oniki parçadan ibaret olan örtüleri yine ipekten yapılmış ve hesap işlemeli çay takımı, İstanbul'un manzaralarını gösteren bir albüm, ${ }^{14}$ Ankara için hazırlanmış yaldızlı bir albüm, Osmanlıca harflerle süslenmiş kıymetli bir seccade, bir kılıç ve bir at hediye edilmiştir. ${ }^{15}$

Türkiye ile Afganistan arasındaki bu dostluk havası, Ortadoğu'da ve Hindistan'da çıkarları olan ve o dönemde oldukça zor durumda bulunan İngilizleri endişelendirmiş, Afgan Kralının Türkiye ziyareti İngiltere'nin Ankara Büyükelçisi Sir G. Clerk tarafından dikkatle izlenmiştir. ${ }^{16}$

\section{II- Iran Şahı Rıza Pehlevi'ye Sunulan Hediyeler}

Yüzyıllara dayanan Türk-İran ilişkilerine zaman zaman dostluk havası, zaman zaman da soğuk ilişkiler ve savaşlar hakim olmuştu. Atatürk dönemi Türk-İran ilişkileri de başlangıçta olumsuz seyrediyordu. Bunun da başlıca nedeni Türkiye'nin doğusunda faaliyet gösteren Kürt isyancıların İran'dan destek görmeleri ve bazı sınır anlaşmazlıklarıydı. Ancak Nisan 1925'de İran'da Kaçar Hanedanlığının yıkılıp yerine Pehlevi Sülalesi'nin geçmesi Türk-İran ilişkileri için yeni bir başlangıç oldu. 25 Nisan 1926'da kendisini İran Şahı ilan eden Rıza Pehlevi, sınır anlaşmazlıklarını çözüp Türkiye ile iyi ilişkiler kurmayı ve yapacağı reformlar için yardım almayı amaçlıyordu. ${ }^{17}$ İran'ın bu yeni tutumu Türkiye'de olumlu karşılanmıştı. Nitekim Mustafa Kemal Paşa, Şah Rıza Pehlevi'nin taç giyme törenine bir heyet göndermiş ve Şah'a kıymetli taşlarla süslenmiş bir kılıç hediye etmiştir. ${ }^{18}$

$"$ Ömer Erden, Mustafa Kemal Atatürk Döneminde Türkiye’yi Ziyaret Eden Yabancı Devlet Başkanları ve Bu Ziyaretlerin Türk Basınındaki Akisleri, Basılmamış Yüksek Lisans Tezi, Erzurum, 2002, s. 7.

${ }^{12}$ Cumhuriyet, 7 Mayıs 1928.

${ }^{13}$ Atatürk'ün Milli Dış Politikası II, Ankara, 1994, s. 160-165.

${ }^{14}$ Cumhuriyet, 7 Mayis 1928.

${ }^{15}$ BCA, 030/18/01/02/82/519; BCA, 030/18/01/01/028/25/19; Cumhuriyet, 15 May1s 1928.

${ }^{16}$ Şimşir, Atatürk ve Yabancı Devlet Başkanları I, s. 35.

${ }^{17}$ Mehmet Saray, Türk-İran İlişkileri, Ankara, 1999, s. 109-112.

${ }^{18}$ BCA, 03/18/01/01/018/28/6. Bu kılıç Birinci Dünya Savaşı sırasında Afganistan Emiri Habibullah Han'a hediye edilecekmiş. Afganistan'a Osmanlı Sefiri olarak tayin edilen Eski İzmir Mebusu Abdullah Efendi kılıcı Habibullah Han'a takdim etmekle 
Şah Rıza Pehlevi, bu hediyeden çok memnun olmuş ve duygularını şöyle ifade etmiştir:

"Bu, yalnız bir dost yadigarı değil, bir kardeş yadigarıdır, nezdimde mevkii büyüktür. Gazi Hazretlerinin hediyeyi bu hediyeyi bana bu dört zabit ile gönderdiğine ne derece memnun olduğumu ifade edemem, bunları gördükçe insanın sinesi iftihar ve ümit ile doluyor..."19

Türk-İran ilişkileri Şah Rıza döneminde giderek olumlu bir seyir izlemiştir. Mustafa Kemal Paşa, İran'daki yeni yönetime verdiği önemi göstermek bakımından Milli Mücadelede ve daha sonraki dönemde devamlı yanında bulunan arkadaşlarından Hüsrev Gerede'yi Tahran Elçiliği'ne atamıştır. ${ }^{20}$ İki ülke arasındaki bu yakınlaşmanın bir sonucu olarak önce 14 Mart 1932'de sınır güvenliği ile ilgili bir anlaşma, daha sonra da 5 Kasım 1932'de yeni bir "Dostluk, Tarafsızlık ve Ekonomik İşbirliği Antlaşması”" imzalanmıştır. ${ }^{21}$

$\mathrm{Bu}$ Antlaşmaların imzalanmasından sonra Türkiye ile İran arasındaki ilişkiler dostane bir havaya girmiş, İran Şahı Rıza Pehlevi'nin 1934 Haziranında Türkiye'yi ziyaret etmesiyle bu dostane ilişkiler daha da pekişmiştir. $^{22}$

Türkiye ziyareti sırasında Türk halkı ve Atatürk tarafından sıcak bir şekilde karşılanan Şah Rıza Pehlevi'ye çeşitli hediyeler verilmiştir. Bu hediyelerden en önemlisi Kayseri Fabrikası'nda üretilen uçaktı. ${ }^{23}$ Bundan başka Rıza Şah'ın ziyaret hatırası olarak darphanede 150 adet madalya bastırılmıştı. Madalyanın bir tarafında Mustafa Kemal Paşa'nın diğer tarafında Rıza Şah'ın resimleri vardı. Resimlerin altına "İ̀an Şehinşahı Ala Hazret-i Hümayun Rıza Şah Pehlevi Hazretleri'nin Türkiye Cumhur Reisi Gazi Mustafa Kemal Hazretlerini Ziyaretleri Hatırası" cümlesi yazılıydı.

Bu cümle Mustafa Kemal Paşa'nın resminin altına Türkçe, Rıza Şah'ın resminin altına Farsça yazılmıştı. Madalyanın birisi altından diğerleri gümüş ve bronzdan yapılmış, altın madalya Rıza Şah'a, gümüş ve bronz madalyalar

görevlendirilmiş, ancak Abdullah Efendi oraya ulaşamamış, bir süre sonra da Habibullah Han bir suikaste kurban gitmişti. (Bilâl N. Şimşir, Bizim Diplomatlarımız, Ankara, 1996, s. 92).

${ }^{19}$ Şimşir, Atatürk ve Yabancı Devlet Başkanları II, Ankara, 2001, s. 445.

${ }^{20}$ Günay Çağlar, "Atatürk'ün Tahran Büyükelçisi Hüsrev Gerede Zamanında Türkiye-İran İliş̧ilerine Bir Bakış, 1930-1934 Yılları Arasında Türkiye ve Dünya”, Atatürk IV. Uluslar arası Kongresi, Ankara, 2000, s. 981.

${ }^{21}$ Saray, Türk-İran İlişkileri, s. 117.

22 Saray, Türk-İran İlişkileri, s. 117; Pierre Oberling, "Atatürk and Reza Shah", I. Uluslararası Atatürk Sempozyumu (21-23 Eylül 1987), Ankara, 1994, s. 651; Cumhuriyet Ansiklopedisi (1923-2000) I, İstanbul, 2003, s. 229.

${ }^{23}$ BCA, 030.18.01/46.45.13; Cumhuriyet, 3 Haziran 1934. 
ise Şah'ın maiyetindeki zevata verilmişti. ${ }^{24}$ Ayrıca Rıza Şah'a değerli bir albüm de hediye edilmişti. ${ }^{25}$

Şah Rıza Pehlevi'nin Türkiye ziyareti her iki ülke basınında da geniş yer almış, iki ülke ilişkilerini öven yayınlar yapmışlardır. ${ }^{26}$

\section{III-Irak Kralı Faysal'a Sunulan Hediyeler}

Cumhuriyet dönemi Türkiye-Irak ilişkileri, "Musul Sorunu" ve İngiltere'nin Irak üzerindeki mandaterliği nedeniyle başlangıçta soğuktu ve Atatürk, Irak'a karşı mesafeli bir tutum izliyordu. Hatta Irak Kralı Faysal daha önce Türkiye'yi ziyaret etmek istemesine rağmen Atatürk, Türkiye'nin Bağdat elçisi vasıtasıyla Kral Faysal'ın ziyaretinin teşvik edilmemesini istemişti. ${ }^{27}$ Ancak Ingiltere ile Irak arasında 30 Haziran 1930'da imzalanan Antlaşmasıyla Irak'a muhtariyet verilmesi ve daha sonra bölgede ve dünyada meydana gelen son gelişmeler iki ülkeyi giderek birbirine yaklaştırmıştır. Irak Kralı Faysal'ın 6-8 Temmuz 1931 tarihlerinde Türkiye'yi ziyareti ise ilişkilere bir dostluk havası kazandırmıştır. Kral Faysal ve maiyetine hediye edilen resimler ise bu dostluğu pekiştirmiştir. ${ }^{28}$

\section{IV-Ingiltere Kralı VIII. Edward'a Sunulan Hediyeler}

Birinci Dünya Savaşı'ndan sonra İngilizlerin düşmanca faaliyetleri sonucunda Türk halkı büyük çileler çekmiş fakat büyük millet ve devlet ciddiyetinde hareket ederek kendisine kötülük yapan diğer millerde olduğu gibi İngilizlere karşı da hiçbir kin beslememişti. Nihayetinde Türk milletinin sinesinden çıkmış olan ve O'nun duygularını en güzel şekilde ifade eden Büyük önder Atatürk, bütün bu kötü maziye rağmen İngilizlerden "karakter sahibi bir millet" diyerek bahsetmişti. ${ }^{29}$

Lozan Antlaşması'ndan arta kalan sorunlardan Musul Meselesi İngiltere ile Türkiye arasındaki ilişkilerin gelişmesini bir süre engellemişti. Ancak, Türkiye'nin yaptığı inkılaplarla hedefinin batı olduğunu göstermesi, bölgesinde modern ve güçlü bir devlet olarak ortaya çıkması ve Avrupa'da savaş rüzgarlarının esmeye başlaması iki ülkeyi birbirine yaklaştırmıştı. İşte bu sırada Akdeniz'e yat gezintisine çıkan Kral VIII. Edward'ın Türkiye'ye uğraması ise ilişkilerin işbirliği ve dostluk seviyesine ulaşmasına vesile olmuştu. ${ }^{30}$

${ }^{24}$ Hakimiyet-i Milliye, 3 Haziran 1934.

${ }^{25}$ Cumhuriyet, 4 Haziran 1934

${ }^{26}$ Hakimiyet-i Milliye, 14 Haziran 1934; Cumhuriyet, 15 Haziran 1934.

${ }^{27}$ Şimşir, Atatürk ve Yabancı Devlet Başkanları II, s. 248.

${ }^{28}$ Şimşir, Atatürk ve Yabancı Devlet Başkanları II, s. 271.

29 Philip Graves, İngilizler ve Türkler, Osmanlıdan Günümüze Türk-İngiliz İlişkileri (1789-1939), (Tercüme: Yılmaz Tezkan), Ankara, 1999, s. 157.

30) İngiltere Hükümeti, Kralın gezintisi hakkında Türkiye'ye bilgi vermiş ve Kralın bu seyahati esnasında Türkiye limanlarında ve sahillerinde istirahat etmek istediği takdirde 
3 Eylül 1936 günü Çanakkale'ye gelen ve burada çeșitli ziyaretlerde bulunan $^{31}$ Kral VIII. Edward, 4 Eylül 1936 günü İstanbul'a geldi. ${ }^{32}$ Kral Edward'ı törenle karşılayan Atatürk, ${ }^{33}$ O'na büyük ilgi göstermiş ve bir ara sohbet esnasında ikram ettiği sigarayı çok beğenmesi üzerine iki sandık sigara hediye etmiştir. ${ }^{34}$

Türkiye ziyaretinden çok memnun ayrilan Kral VIII. Edward'a Atatürk daha sonra kendi fotoğrafından başka Türkiye'yi ziyareti esnasında çekilmiş fotoğraflar, Matbuat Umum Müdürlüğü tarafından tertip edilmiş bir albüm, bu ziyaret vesilesi ile Türkiye'deki çeşitli gazetelerde yer alan fotoğraf ve haberler (ki ayrı ayrı ebatta ciltlenmiş ve iki albümde toplanmıştı) ve yine ziyaret sırasında amatörler tarafından çekilmis fotoğraflardan olușan bir takım hediye göndermiş ve bu hediyeler Türkiye'nin Londra Büyükelçisi Fethi Okyar tarafından 25.11. 1936'da Kral VIII. Edward'a takdim edilmiştir. ${ }^{35}$

\section{V-Almanya Cumhurbaşkanı Mareşal Von Hindenburg'a Gönderilen Hediye}

XX. yüzyıl başlarında güçlü bir konuma ulaşan Türkiye-Almanya iliş̧ileri, I. Dünya Savaşı sonrası İtilaf bloğunun da etkisiyle kesintiye uğramışsa da, her iki tarafta yeni rejimlerin kurulmasıyla tekrar başlamış ve giderek gelişmiştir. Bu dönemde Almanya Cumhurbaşkanı Mareşal Von Hindenburg ile Mustafa Kemal Paşa birbirlerine imzalı fotoğraflarını hediye ederek iki ülke arasındaki dostluk ilişkilerine katkıda bulunmuşlardır. ${ }^{36}$

\section{VI- Almanya Devlet Başkanı Adolf Hitler'e Gönderilen Hediye}

Alman Nasyonal Sosyalizminin lideri olan Adolf Hitler, Alman halkının içinde bulunduğu ekonomik ve sosyal sıkıntıların etkisiyle kısa sürede güçlenmiş, mecliste çoğunluğu ele geçirmiş ve başbakan olmuştur. Cumhurbaşkanı Hindenburg'un ölümü ile de devlet başkanlığını ele geçirmiştir.

Avrupa devletlerinin korkulu rüyası olan Adolf Hitler, Mustafa Kemal Atatürk'e saygı duymakta ve değer vermekteydi. Atatürk de iki ülke

gerekli müsaadenin verilmesini istemişti. (BCA, 18/239.102.1936). Bu yazıya olumlu cevap verilmiş ve bu konudaki gerek kararname 11 Ağustos 1936'da onaylanmıştı. (BCA, 030/01.67.681).

${ }^{31}$ Akşam, 4 Eylül 1936

${ }^{32}$ Akşam, 5 Eylül 1936.

${ }^{33}$ Enver Behnan Şapolyo, Kemal Atatürk ve Milli Mücadele Tarihi, İstanbul, 1958, s. 516.

${ }^{34}$ Cemal Granda, Atatürk'ün Ușağı İdim, İstanbul, 1959, s. 365.

${ }_{35}$ Kral VIII. Edward da İstanbul seyahati ile ilgili 5 fotoğrafı İngiltere'nin Türkiye Büyükelçisi vasıtasıyla Atatürk'e takdim etmiştir. (Şimşir, Atatürk ve Yabancı Devlet Başkanları II, 362-365).

${ }^{36}$ Şimşir, Atatürk ve Yabancı Devlet Başkanları I, s. 137. 
arasındaki ilişkileri geliştirmek, bölge ve dünya barışına katkıda bulunmak amacındaydı. Nitekim Atatürk, iki ülke arasındaki rutin resmi yazışmaların ve kutlamaların önüne geçmiş ve Adolf Hitler'e imzalı bir resmini göndermiştir. ${ }^{37}$

Atatürk'ün, kendisine imzalı resmini göndermesinden büyük memnunluk duyan Adolf Hitler, bu memnuniyetini Mustafa Kemal Atatürk'e gönderdiği 13 Ağustos 1937 tarihli mektubunda şöyle ifade etmekteydi:

"Bay Cumhurbaşkanı,

Siz Ekselans, Büyükelçiniz Bay Hamdi Arpağ vasıtasıyla, bana kalbi temennilerinizle beraber resminizi göndermek lütfunda bulunmuşsunuz. $\mathrm{Bu}$ münasebetle siz Ekselans tarafından izhar buyurulan ve bütün Alman halkınca şükranla karşılanan dostane hislerden dolayı size samimiyetimi, teşekkürlerimi ifade benim için hakiki bir ihtiyaç olmuştur. Hakkımda gösterilen nezakete, milletlerimizi bağlayan dostluk münasebeti için yeni bir delil görüyorum.

$\mathrm{Bu}$ fırsattan istifade ederek, Türk milletinin inkişafla devamı ve siz Ekselansın şahsi saadeti hakkında en hararetli temennilerimi sunarım.,38

\section{VII- Italya Kralı Victor Emanuel'e Gönderilen Hediyeler}

İtalya ile Türkiye arasındaki ilişkiler Lozan Barış Antlaşması'ndan sonra belli bir süre gelişme kaydetti ve Atatürk, İtalya ile en üst düzeyde ilişki kurmaya çalıştı. 1926 yılında İtalya Ana Kraliçesi Marguerita öldüğünde Atatürk, Kral Victor Emanuel'e bir mesaj göndererek başsağlığı dilemiş, İtalyan Kralı da ertesi yıl Atatürk ikinci kez Cumhurbaşkanı seçilince bir kutlama telgrafı göndermiştir. 1928 yılında da Atatürk, özel sigarasından bir miktarını hediye olarak Kral Emanuel'e göndermiş ve daha sonra da İtalyan Kralı ve ailesine karşı yakın ilgisini sürdürmüştür. Nitekim 1929'da İtalyan Veliahtı Prens Humbert nişanlanmış, Atatürk, Kral ve Kraliçeyi kutlamış, ertesi yıl Veliaht evlenmiş, Atatürk düğünde temsil edilmiş ve yeni evlilere bir Hereke halısı hediye etmiştir. ${ }^{39}$

\section{VIII-Yugoslavya Kralt I. Alexandre'a İthaf Edilen Hediye}

Birinci Dünya Savaşı'nın taraf ülkelerinden birisi olması açısından Lozan Konferansı'na katılan Yugoslavya ${ }^{40}$ Barış Antlaşmasını

${ }^{37}$ Şimşir, Atatürk ve Yabancı Devlet Başkanları I, s. 166-167.

${ }^{38}$ Şimşir, Atatürk ve Yabancı Devlet Başkanları I, s. 167-168.

${ }^{39}$ Bilal N. Şimşir, Atatürk ve Yabancı Devlet Başkanları III, Ankara, 2001, s. 144.

40 1 Aralık 1918 tarihinde Sırbistan, Hırvatistan, Slovenya, Bosna-Hersek ve Karadağ'dan oluşan "Sırp-Hırvat-Sloven Krallı̆̆ı” olarak ortaya çıkmış, 1929'da kabul edilen yasa ile bu devletin adı Yugoslavya Krallığı olarak değiştirilmişti. (Hikmet Öksüz, Atatürk Döneminde Balkan Politikası (1923-1938), Türkler Ansiklopedisi, cilt: 16, s. 625). 
imzalamamıştı. Bundan dolayı Türkiye ile Yugoslavya arasındaki savaş durumu devam ediyordu. Ancak 28 Ekim 1925 tarihinde imzalanan "Dostluk Paktı" iki ülke arasındaki savaş durumuna son verdiği gibi ikili ilişkiler için bir başlangıç teşkil etmiştir. ${ }^{41}$

Yugoslavya Kralı I. Alexandre'1n 4-5 Ekim 1933 tarihlerinde Türkiye'yi ziyareti ve Atatürk'le yaptığı görüşme ise iki ülke arasındaki ilişkilerin gelişmesinde ve Balkan Birliği'nin kurulmasında büyük rol oynamıştır. ${ }^{42}$

Kral Alexandre'ın 7 Ekim 1934'de Fransa'ya yaptı̆̆ı bir ziyaret esnasında Borsa Meydanı'nda bir Hırvat tarafından öldürülmesi Türkiye'de büyük üzüntüye neden olmuştu. ${ }^{43}$ Çünkü Kral Alexandre Balkan Antantı'nın ve bölge barışının mimarlarından birisiydi. ${ }^{44} \mathrm{Bu}$ barış adamının çabalarını unutamayan Atatürk, O'na ithaf edilmek üzere altın plaka üzerine büyük bir portre hediye etmiştir $(9.07 .1937){ }^{45}$

\section{Hediye}

IX-Amerika Birleşik Devletleri Başkanı Roosevelt'e Gönderilen

$X X$. yüzyılın başından itibaren dünya siyasetinde ağırlığını hissettirmeye başlayan Amerika Birleşik Devletleri ile Ortadoğu'nun genç ve dinamik devleti olan Türkiye Cumhuriyeti'nin ilişkileri özellikle Roosevelt döneminde büyük gelişme kaydetmişti. ABD tarihinin en ağır ekonomik bunalımı sırasında başkanlık koltuğuna oturan Roosevelt (4 Mart 1933), üst üste reformlara girişti. Roosevelt aynı zamanda dünya barışının korunması konusuyla da yakında ilgileniyordu. Roosevelt'in bu reformcu ve barışsever yapısı Atatürk ile Roosevelt yakınlaşmasının en önemli özelliği olmuştur. ${ }^{46}$

${ }^{41}$ Soysal, Türkiye'nin Siyasal Antlaşmaları I, s. 248.

${ }^{42}$ Atatürk'ün Milli Dış Politikası II, Ankara, 1994, s. 225-227). Yugoslavya Kraliçesi'nin annesi Romanya Kraliçesi ile birlikte 4-11 Mayıs 1932'de özel olarak İstanbul'u ziyaret etmeleri, İstanbul'da Kraliçelere gösterilen yakınlık ve konukseverlik Kralı ve Yugoslav halkını çok memnun etmiş ve Kral Alexandre'ın Türkiye'yi ziyaret etmesine zemin hazırlamıştır. (Şimşir, Bizim Diplomatlarımız, s. 407).

43 Haber Ankara'da adeta şok yarattı. Atatürk'ü ve hükümeti üzüntüye boğdu. Hakimiyet-i Milliye gazetesi, ertesi gün bütün baş sayfasını Yugoslav Kralının ölümüne ayırdı. Türkiye'de bayraklar yarıya indirildi ve Türkiye'de milli yas ilan edildi. (Şimşir. Bizim Diplomatlarımız, s. 277).

${ }^{4}$ Şimşir, Bizim Diplomatlarımız, s. 278.

${ }^{45}$ Şimşir, Atatürk ve Yabancı Devlet Başkanları III, s. 347.

${ }^{46}$ Şimşir, Atatürk ve Yabancı Devlet Başkanları I, s. XIV. 
ABD Başkanı Roosevelt'in pul koleksiyonuna meraklı olduğunu öğrenen ${ }^{47}$ Mustafa Kemal Paşa, kendisine Türk posta pullarından ve Türk Kadınlar Birliği’ne ait pullardan birer seri göndermiştir. ${ }^{48}$

\section{SONUÇ}

Uzun yillar süren savaşlardan sonra adeta harabeye dönmüş olan bir ülkenin ve esaretle yüz yüze kalmış bir milletin liderliğini üzerine almış olan Mustafa Kemal Atatürk, ülkesini ve milletini çağdaşlarının hayranlığını kazanacak bir seviyeye ulaştırmış, izlediği politikalar ve dünya liderleri ile kurduğu dostluk ilişkileri sayesinde Türkiye'yi kısa sürede bir çok devletin ittifak yapmak istediği saygın bir devlet konumuna getirmiştir.

${ }^{47}$ ABD Türkiye Büyükelçisi, Mart 1935 'de Dışişleri Bakanlığı'na müracaatla, pul koleksiyonculuğuna çok meraklı olan Amerika Birleşik Devletleri Başkanı Roosevelt'e gönderilmek üzere, yeni çıkacak olan posta pullarımızdan zamksız bir takımının bedeli mukabilinde kendisine verilmesi arzusunu bildirmiş, elçinin bu dileğini öğrenen Atatürk de, anılan pulların bizzat kendileri tarafından Başkan Roosevelt'e gönderilmesi için gerekli hazırlıkların yapılmasını istemişti. (Şimşir, Atatürk ve Yabancı Devlet Başkanları I, s. 242).

${ }^{4 \times}$ Şimşir, Atatürk ve Yabancı Devlet Başkanları I, s. 242-245. 